\title{
GESTÃo E CURRICULARIZAÇÃO DA EXTENSÃo EM UMA UNIVERSIDADE COMUNITÁRIA: DO REQUISITO ACADÊMICO AOS DESAFIOS DA IMPLEMENTAÇÃO
}

DOI: dx.doi.org/10.18616/inser03

Bernadete Maria Dalmolin ${ }^{1}$

Adriano José Hertzog Vieira ${ }^{2}$

Julio Cesar Godoy Bertolin ${ }^{3}$

\section{INTRODUÇÃOO}

O lugar da gestão configura-se como instituição dentro de instituições. Por isso, constitui-se impregnado de uma mitologia que o funda e o sustenta. Marilena Chauí (2001), no livro "Brasil, Mito Fundador e Sociedade Autoritária”, postula uma relação arquetípica, simbólica, com tudo o que é construído institucionalmente pelos grupos sociais. As funções de gestão, como produto institucional, são eivadas de significados projetivos das inúmeras subjetividades a elas relacionadas. Portanto, identificar, compreender e desconstruir essa miríade de projeções, desmitificando a gestão, formula-se em pressuposto para se pensar a efetividade gerencial como catalisadora de um projeto social, humanizado e promotor da auto-

${ }^{1}$ Doutora em Saúde Pública. É docente do Instituto de Ciências Biológicas e Vice-Reitora de Extensão e Assuntos Comunitários da Universidade de Passo Fundo/RS. E-mail: berna@upf.br

${ }^{2}$ Doutor em Educação: Aprendizagem, Currículo e Formação Docente. Atualmente, é diretor do Instituto Transdisciplinar de Formação Saber Cuidar e assessor pedagógico da vice-reitoria de extensão da Universidade de Passo Fundo/RS.

${ }^{3}$ Doutor em Educação. Atualmente, é professor titular e pesquisador da Universidade de Passo Fundo/RS. 
nomia, da subjetivação e do comprometimento com a qualidade de vida inclusiva, democrática e libertadora.

Escrevemos este capítulo motivados por uma experiência de gestão acadêmica da Vice-Reitoria de Extensão e Assuntos Comunitários da Universidade de Passo Fundo, no período de 2011-2013, e, atualmente, pelos desafios da segunda gestão (2014-2018).

O texto ainda se configura em sistematização de fundamentos capazes de colaborar na busca de novos sentidos para práticas acadêmicas oriundas da extensão, na interconexão com as demais áreas que constituem o modo de ser da universidade, ou seja, o ensino e a pesquisa.

Nesse contexto, conscientes de que a gestão, considerando os argumentos já pautados, é atribuição representativa dos anseios de uma coletividade, precisamos das duas seguintes questões: em que sentido a extensão pode contribuir para o aprofundamento do ensino e da pesquisa e, em que medida, também, pode se deixar ser por eles alimentada? Qual é o papel da extensão, em uma ideia transversal de universidade, que possa oferecer formação profissional de excelência, alicerçada na formação humana, crítica e autônoma? ${ }^{4}$

Tem sido recorrente, no cotidiano de nossa trajetória docente, ouvir comentários que expressam a dificuldade no processo ensino-aprendizagem. Os professores manifestam a percepção da precariedade acadêmica com que estudantes chegam à universidade, sem o suporte necessário para um aproveitamento mais global para o que a educação superior oferece. De outra parte, colecionam-se manifestações que constatam a qualidade diferenciada da formação dos estudantes que vivenciam, no ensino, a experiência em projetos de pesquisa e extensão. Tais manifestações ensejam a possibilidade de se pensar a necessária, e já reconhecida, formação integral

${ }^{4}$ Os documentos que embasam a Universidade de Passo Fundo, como o Projeto Político Institucional (PPI) e o Plano de Desenvolvimento Institucional (PDI), trazem esses princípios no seu escopo. 
para a constituição das subjetividades ${ }^{5}$, sempre nas relações intersubjetivas. Os estudantes, por sua vez, expressam o descontentamento com uma rotina de ensino cansativa, baseada na exposição conteudista; reclamam do distanciamento acadêmico das especificidades profissionais para as quais estarão se formando; ressentem a falta de tempo para se dedicar ao estudo. Se aprofundarmos essas manifestações, sem querer justificá-las de imediato, encontraremos sinais e evidências de uma proposta de educação superior que urge ser repensada. Nesse contexto, a gestão acadêmica tem um papel fundamental, particularmente quando também propõe a si mesmo a tarefa de se repensar.

No campo da gestão, temos a responsabilidade e o compromisso de aproximar cada vez mais a realidade à formação a ser desenvolvida durante o percurso acadêmico. Percebemos a complexidade dessa equação, especialmente neste momento histórico em que o mundo da informação ${ }^{6}$ nos "atropela" a cada dia, exigindo-nos respostas mais velozes e conexões da ordem da complexidade. Ao mesmo tempo, boa parte de nossa base formativa está arraigada em modelos (teorias, metodologias e práticas) bas-

\footnotetext{
${ }^{5}$ Subjetividade é aqui entendida no sentido dado por Félix Guattari. O autor considera a subjetividade sob o ângulo da produção, ultrapassando a visão clássica de modelos do inconsciente. Compreende-a como um fluxo contínuo de sensações, modos de existir, amar e comunicar, de imagens, sons, afetos, valores e formas de consumo, literalmente fabricadas no entrecruzamento de instâncias sociais, técnicas, institucionais e individuais. No limite, é possível talvez considerar que todos os sujeitos e coletivos humanos, institucionalizados ou não, com maior ou menor grau de instrução e de conhecimento tecnológico, são produtores de subjetividade (GUATTARI, 1992). Assim, as escolhas e os processos vividos na universidade também são produtores de subjetividades.

${ }^{6}$ Sobre esse tema, consultar Jorge Larrosa Bondía (2002). Referido professor comenta que a sociedade da informação (atual) deforma mais do que forma. Em "Notas sobre a Experiência e o Saber da Experiência”, o autor argumenta que isso se dá pelo excesso de informação, pelo fato de a informação não ser experiência e, praticamente, não deixar lugar à experiência.
} 
tante tradicionais ${ }^{7}$, fruto de um processo histórico e fragmentado de fazer ciência e de ensinar.

O tensionamento está posto: temos, no mesmo campo de atuação, professores, alunos, funcionários, sociedade em geral, todos com expectativas, saberes e uma infinidade de subjetividades, cabendo à universidade (especialmente à sua gestão) mediar essas relações com sensibilidade e responsabilidade social, a fim de efetivar seu papel. No caso da Universidade de Passo Fundo (UPF), tal missão consiste em “[...] produzir e difundir conhecimentos que promovam a melhoria da qualidade de vida e formar cidadãos competentes, com postura crítica, ética e humanista, preparados para atuarem como agentes de transformação." (UNIVERSIDADE DE PASSO FUNDO, 2011, n.p.).

No esforço de construir um projeto coletivo para a UPF, partilhando de motivações semelhantes às mencionadas, um grupo de pessoas desejosas (professores, alunos, funcionários e representantes da comunidade) esboçou uma proposta para o quadriênio 2014-2018 (Projeto Somos Todos UPF, 2014), pautada nos seguintes eixos estruturantes: Excelência Acadêmica, Sustentabilidade Acadêmico-Financeira e Responsabilidade Social. Sobre a Excelência Acadêmica, diz o documento:

Em um mundo cada vez mais plural e complexo, com diferentes e variadas formas de vida, o que faz a diferença é FORMAR um sujeito crítico, ético, aberto ao diálogo, com capacidade de pensar por si mesmo, com olhar abrangente, sensibilidade

\footnotetext{
${ }^{7}$ Em "Educação em Sociedades Tradicionais e Sociedades Complexas: o problema da crise de autoridade", o professor Claudio Dalbosco (UPF) questiona como a educação escolar pode enfrentar a crise da autoridade e o conflito de gerações que assolam a cultura contemporânea. Constrói seu argumento em torno da educação tradicional, predominantemente autoritária e hierárquica versus a sociedade contemporânea, globalizada e digitalizada, cuja autoridade cede lugar, em especial, à celebridade. Sustenta que a difícil tarefa requer o exercício de "[...] mediar esse conflito, oferecendo os recursos intelectuais às novas gerações para que, por meio do estudo paciencioso e sistemático do legado cultural das gerações mais velhas, possam compreender a si mesmas." (DALBOSCO, 2015a, p. 23).
} 
imaginativa e responsabilidade social. (UNIVERSIDADE DE PASSO FUNDO, 2014, p. 4. Grifos nossos).

O projeto traz, em seu núcleo, a necessidade de aprimorar a qualidade na formação ${ }^{8}$, traduzida pela excelência acadêmica:

A Excelência acadêmica repousa na busca coletiva pela qualidade do ensino, da pesquisa e da extensão [em um movimento integrador e indissociável]. Nessa perspectiva, a excelência desejada só se concretiza quando em cada curso, em cada ambiente acadêmico - seja em sala de aula, no laboratório ou em outros espaços - os sujeitos envolvidos fazem com que as relações estabelecidas e os conhecimentos construídos contribuam para a formação da cidadania e para o desenvolvimento social. É no currículo transversalizado que ensino, pesquisa e extensão, entrelaçados, podem promover a criatividade, a inovação, o desenvolvimento e a transformação da sociedade. (UNIVERSIDADE DE PASSO FUNDO, 2014, p. 5. Grifos nossos).

Diante da aprovação democrática desse projeto pela comunidade universitária, que agrega os sonhos e os desejos dos sujeitos na intersubjetividade, torna-se relevante, a partir do lugar da gestão, ampliar a reflexão para criar condições contextualizadas, inovadoras e factíveis a partir da extensão, à luz do princípio da indissociabilidade com o ensino e com a pesquisa. Para essa construção, propomos uma discussão sobre a indissociabilidade, o currículo e acurricularização da extensão. Na sequência, apresentamos algumas estratégias de intervenção. A fundamentação está na estratégia argumentativa da transversalidade como "mecanismo garan-

${ }^{8} \mathrm{O}$ professor da UPF, colaborador na proposta de gestão, aprofunda questões referentes à qualidade na formação no texto "Educação Superior e os Desafios da Formação para a Cidadania Democrática” (DALBOSCO, 2015b). 
tidor" da indissociabilidade acadêmica, em consonância com o projeto de gestão mencionado.

\section{CURRICULARIZAÇ̃̃O DA EXTENSÃO NA PERSPECTIVA DA INDISSOCIABILIDADE}

Antes de adentrar nesta discussão, é oportuno expor alguns traços gerais do cenário da educação superior, em especial de um processo de transformações que referida educação vem experimentando nas duas últimas décadas. Estudiosos da área relacionam as transformações da educação superior a um conjunto de variáveis que tem como base principal o sistema econômico global, que traz a necessidade de um profissional com formação técnica profissionalizante para atender às necessidades do mercado, em um tempo de formação cada vez mais reduzido e a um baixo custo financeiro. Associados a isso, agregam-se, ainda, a escassa formação (especialmente pedagógica) dos professores e a precária formação da educação básica.

Segundo o professor Júlio Bertolin (2011), essa realidade levou os sistemas nacionais de educação superior de diversos países a incentivarem reformas nessa educação, que, por sua vez, provocou a expansão das redes de instituições privadas, a redução dos financiamentos públicos e o aumento da competitividade no provimento de serviços educacionais. Como consequência, o autor adverte que a educação superior passa a ser reorientada "[...] de acordo com os princípios e a lógica do mercado, perdendo, gradativa e progressivamente, o status de bem público e assumindo a condição de serviço comercial." (BERTOLIN, 2011, p. 239).

Em que pese a importância da formação profissional - competente técnica e cientificamente - para atender às necessidades do mercado, as transformações acima explicitadas influenciaram diretamente a quali- 
dade da formação como um todo, em particular aquela que poderá dar uma formação cultural mais ampla, capaz de abarcar problemas típicos de uma sociedade plural e interconectada. Cláudio Dalbosco, ao analisar esse cenário, baseando-se na tese de Martha Nussbaum ${ }^{9}$, defende a ideia de que a formação para o exercício da cidadania precisa estar fundada em três pilares: "[...] o pensamento crítico, a cidadania universal e a capacidade imaginativa." (DALBOSCO, 2015b, p. 125). Contudo, reforça o autor que a tendência da educação superior é ficar cada vez mais privada dessa “[...] perspectiva humanista, representada, por exemplo, pelas artes, letras, direito e filosofia." (DALBOSCO, 2015b, p. 125).

Antonio Nóvoa, ao apresentar os principais problemas enfrentados pelo ensino superior (SANTOS, 2012), também destaca, dentre outros aspectos, a necessidade de um corpo de conhecimentos sólidos e de relevância social. Como escrito em um importante documento da League of European Research Universities, o autor destaca algumas qualidades de que tanto se fala no contexto atual, como empreendedorismo, capacidade de gestão, liderança e trabalho de grupo, que não são características primárias, mas decorrem da capacidade de pensar, de argumentar e de conhecer. Toma como preocupação, no atual contexto, o significativo percentual de estudantes que têm insucesso ou que abandonam os estudos logo nos primeiros anos da universidade, bem como aqueles cuja obtenção de um diploma de pouco ou nada serve (SANTOS, 2012).

Outra dimensão importante a ser considerada no cenário atual da educação superior e sobre a qual muitos estudiosos tecem críticas, é o reconhecimento da formação pedagógica como uma especificidade do seu trabalho. Nesse quesito, há a necessidade de compreender a importância dos saberes profissionais de determinadas áreas, mas, juntamente a essas, há também a necessidade de capacitar pedagogicamente o professor universitário, a fim de ampliar suas potencialidades de ensinar e de aprender.

${ }^{9}$ NUSSBAUM, M. C. Sin fines de lucro: Por qué la democracia necesita de las humanidades. Buenos Aires: Katz Editores, 2010. 
O desafio posto às Instituições de Ensino Superior (IES) para enfrentar essa realidade e cumprir com sua finalidade maior, que é formar cidadãos competentes, com postura crítica, ética e humanista, preparados para transformar a realidade, é complexo e multifacetado. Sem dúvida, esse contexto exige refletir continuamente sobre o sentido da formação oferecida e como dar conta de contemplar as principais dimensões e racionalidades humanas, sem priorizar uma em detrimento de outra, reconhecendo diferentes públicos e situações.

\section{COMEÇANDO PELA INDISSOCIABILIDADE}

O olhar sobre a indissociabilidade entre ensino, pesquisa e extensão é recente nas universidades brasileiras, assim como em outros países da América Latina e do mundo. Ela surge nesse cenário impulsionada por, pelo menos, duas questões centrais: a necessária superação da fragmentação do conhecimento e da formação e uma universidade mais comprometida com o seu contexto social. De outra parte, a indissociabilidade nasce da necessária vinculação entre o conhecer e o viver e demanda de um presente epistemológico constatado por vários pensadores, como Boaventura Santos (2011), Edgar Morin (2000), Basarab Nicolescu (2000), Maria Cândida Moraes (2012), dentre outros. Para esses autores, a complexa dinâmica da realidade exige um conhecimento que contemple as possíveis dimensões humanas e sociais, transcendendo ao universo racional e abarcando as experiências pessoais, os relacionamentos, os desejos e as emoções. A universidade tem sido, ao longo de sua história, espaço de tensões e de disputas entre diferentes projetos de sociedade, dentre os quais faremos referência a apenas alguns marcos que podem ilustrar momentos significativos na América Latina e no Brasil.

Em 1918, o Manifesto de Córdoba ou Movimento pela Reforma Universitária Latino-Americana reivindicou universidades democráticas 
com alto nível acadêmico e socialmente comprometidas. Na ocasião, fazia referência a uma "terceira função" universitária: a extensão, que, juntamente com o ensino e com a investigação, estreitaria as relações entre universidade e sociedade (AROCENA, 2010).

No Brasil, dois importantes marcos a respeito da indissociabilidade foram a Reforma Universitária de 1968 e a Constituição Federal de 1988. O primeiro, conduzido pelo Estado Militar, em meio a profundas tensões com os movimentos estudantis, prometia a modernização das universidades, que tinham como necessidades a ampliação e a articulação entre ensino e pesquisa e, a partir delas, dar respostas ao mundo do trabalho e a uma sociedade em desenvolvimento, especialmente por meio da prestação de serviços. Apesar das dificuldades de avanço no período, muitos educadores e militantes, como Paulo Freire, Darcy Ribeiro, Álvaro Vieira Pinto, Anísio Teixeira e Ernani Fiori, que haviam construído um grande legado sobre/na educação no Brasil e no exterior, influenciavam na direção de uma pedagogia crítica, libertadora e emancipatória, aberta às necessidades sociais.

O segundo marco foi na década de 1980, precedendo à Constituição de 1988. Maciel e Mazzilli (2010) destacam o importante papel e protagonismo exercido pela Associação Nacional dos Docentes do Ensino Superior (ANDES) na formulação de uma concepção de universidade voltada aos interesses da maioria da população. As teses elaboradas por essa associação têm, no princípio da indissociabilidade entre ensino, pesquisa e extensão, sua ancoragem para a melhoria da qualidade do trabalho acadêmico, uma vez que, por meio dela, seria possível aproximar os conhecimentos e as necessidades existentes, propiciando avaliações coletivas, produzindo conhecimento novo e intervindo de acordo com as necessidades concretas da maioria da população.

As autoras destacam que, por ocasião da elaboração da Carta Constitucional Brasileira de 1988: 
O Fórum Nacional da Educação na Constituinte liderou a aprovação de uma emenda popular que formulava o princípio da indissociabilidade entre ensino, pesquisa e extensão como paradigma de uma universidade socialmente referenciada e expressão da expectativa de construção de um projeto democrático de sociedade, que se tornou o artigo 207 da Constituição. (MACIEL; MAZZILLI, 2010, p. 1).

Diz o artigo Constitucional:

[...] as universidades gozam de autonomia didático-científica, administrativa e de gestão financeira e patrimonial, e obedecerão ao princípio da indissociabilidade entre ensino, pesquisa e extensão. (BRASIL, 1988, n.p.).

Maciel e Mazzilli (2010) fazem uma análise da repercussão desse princípio, considerando as várias tentativas de retirada, por emendas constitucionais, e interpretações equivocadas. Todavia, a aprovação da Lei de Diretrizes e Bases da Educação Nacional, Lei no 9.394/96, e as suas regulamentações possibilitaram que esse princípio estivesse presente nas universidades, ficando os centros universitários e as faculdades dispensados de desenvolver pesquisa e extensão.

Observa-se, então, que a indissociabilidade proposta traz na sua bagagem muitas lutas de professores e outras forças da sociedade civil organizada, que desejavam que o ensino superior brasileiro buscasse a superação da fragmentação do trabalho docente de ensinar, pesquisar e fazer extensão.

A extensão universitária foi reforçada por esses movimentos, por ser a função que traz mais possibilidade de interação social no seu objeto, mas também frequentemente criticada pelo papel assistencialista e acrítico 
com que desenvolvia suas ações, muitas vezes cumprindo (precariamente) o papel do Estado, como o fez no período do governo ditatorial militar.

Garcia (2012), em sua tese de doutorado, sinaliza momentos importantes da extensão nas universidades mundiais e suas funções em diferentes momentos históricos, dentre os quais, destaca: a necessidade de expandir o conhecimento para além dos espaços acadêmicos, a necessidade de capacitar as populações para o mercado de trabalho e a defesa da abertura das universidades para a sociedade.

Alguns desdobramentos da legislação brasileira mais recentes explicitam a extensão nas instituições de ensino, como é o caso da Lei $n^{\circ}$ 12.881 , de 12 de novembro de 2013 , que, em seu artigo $1^{\circ}$, parágrafo $4^{\circ}$ menciona:

As Instituições Comunitárias de Educação Superior institucionalizarão programas permanentes de extensão e ação comunitária voltados à formação e desenvolvimento dos alunos e ao desenvolvimento da sociedade. (BRASIL, 2013, n.p.).

O Plano Nacional de Educação (2014-2024), recentemente aprovado, também tem metas orientadas para a democratização do acesso à educação, com inclusão e qualidade. Nesse sentido, tem destaque a meta 12 , estratégia 12.7, que estabelece a necessidade de "[...] assegurar, no mínimo, $10 \%$ (dez por cento) do total de créditos curriculares exigidos para a graduação em programas e projetos de extensão universitária, orientando sua ação, prioritariamente, para áreas de grande pertinência social." (BRASIL, 2014).

O Sistema Nacional de Avaliação da Educação Superior (Sinaes), por meio dos instrumentos de avaliação institucional, também evidencia aspectos que dialogam com a extensão, quais sejam: a responsabilidade so- 
cial da IES, as políticas acadêmicas, a comunicação com a sociedade e a política de atendimento aos discentes.

Da mesma forma, os documentos institucionais da UPF (PDI, PPI, PPCs) referendam essa necessidade, muito embora seja pouco perceptível como esse processo acontece (ou deveria acontecer) no todo da instituição e em cada curso, respectivamente.

Lembramos, ainda, que a Coordenação de Aperfeiçoamento de Pessoal do Nível Superior (Capes) também considera, na avaliação dos programas de pós-graduação, a inserção social e o processo de interlocução com a graduação como elementos que devem permear todo o percurso stricto sensu.

Observamos, portanto, que o princípio da indissociabilidade entre ensino, pesquisa e extensão está na gênese do papel das universidades ou das pluriversidades, conforme Boaventura de Souza Santos (2011). O autor problematiza os modelos de universidade e defende que a universidade do século XXI seja construída em diálogo ou confronto com outros conhecimentos, de forma transdisciplinar e com responsabilidade social, promovendo alternativas de pesquisa, de formação, de extensão e de organização da universidade como bem público, de forma que, em sua especificidade, esta contribua na identificação e na solução de problemas nacionais e globais.

Contudo, se a indissociabilidade evidencia uma força enquanto referência social, teórica e normativa, ela apresenta, ao mesmo tempo, limites e dificuldades para se efetivar no contexto atual, dominado pela economia global de mercado, pela fragmentação e especialização do saber e pela ausência de uma concepção transversal de universidade. Nesse contexto, a educação superior subsumida pela demanda mercadológica, ao pautar-se pela lógica da racionalização e do lucro, perde enquanto vocação ao conhecimento, esvaziando-se como produtora de cultura e promotora da humanização. Decorre daí a necessária mobilização por uma reflexão que retome a vocação da presença universitária, cujo cerne é a dinâmica curri- 
cular voltada à construção de uma sociedade que promova a qualidade de vida dos sujeitos em todas as suas dimensões.

\section{A QUESTÃO DO CURRíCULO}

No âmbito da gestão de Instituições de Ensino Superior, são infindáveis os elementos e os modos de operar produzidos historicamente pela natureza multifacetada das relações de uma universidade com a comunidade que a abriga. Dentre esses elementos, o currículo constitui-se no eixo em torno do qual a vida acadêmica acontece, sendo uma manifestação importante das concepções e objetivos explícitos ou implícitos dos sujeitos que o definem. Focar a gestão na dinâmica curricular possibilita a sinergia de forças, energias e economias capazes de potencializar o projeto que se quer construir.

Nessa perspectiva, apresentamos a seguir uma breve revisão teórica sobre o currículo, considerando as múltiplas concepções e a complexidade que envolve a sua construção.

Macedo $(2007,2012,2013)$ chama a atenção para o modo como o currículo surge no cenário da educação, ou seja, buscando igualar o sistema educacional ao sistema industrial, em uma perspectiva da Teoria Taylorista, dentre outras. Assim, as relações de poder intrínsecas, as tensões e as contradições permeiam as suas políticas e pautas prioritárias e a necessidade de responder a tantas demandas, desde os desafios de um mundo sempre em transformação até a necessidade de manter um status quo corporativo, dentre outros.

Silva (1999) lança questões que reforçam a necessidade de pensar o currículo enquanto conexão entre identidade e poder, tendo em vista que o currículo também forma significativamente aquilo que somos: nossa identidade, nossa subjetividade. "Está centralmente envolvido naquilo que 
somos, naquilo que nos tornamos e naquilo que nos tornaremos. O currículo produz, o currículo nos produz" (SILVA, 1999, p. 27).

Diante de tantos desafios para o currículo, é necessário analisá-lo sistematicamente, como algo complexo que diz respeito à formação humana e, como tal, suscetível a singularizações, conforme os sujeitos e seus contextos. No corrimão desse diálogo, é importante pautar a gestão acadêmica como mobilizadora da produção de subjetividades, considerando o papel formativo da universidade, em vista da inserção das pessoas nos distintos cenários sociais. Decorre daí outra emergência: pensar a curricularização da extensão universitária, levando em conta a complexidade do conhecimento e a integralidade do ser humano. Por isso a necessária atitude problematizadora do currículo.

Ao compreender o caráter relacional e construcionista desse dispositivo institucional, Macedo (2013) cunha a expressão atos de currículo, que vem justamente trazer a compreensão de que a formação se dá em ato, com todos os elementos que este compõe: sentidos, significados, afetos, conhecimentos prévios, reinterpretações, experiências, etc. É na perspectiva interconectada e processual em que o currículo se desvencilha que o autor credita a sua potência, refletida na qualidade da formação.

Ao trazer essas questões para a realidade das universidades, começa a pulular o seguinte questionamento: Nossos "currículos" são documentos "vivos", em torno dos quais a vida acadêmica acontece, ou, ao contrário, são instrumentos burocráticos para cumprir requisitos legais e que não balizam a vida acadêmica, tampouco a tomada de decisão? Nesse viés, surgem outras questões correlacionadas: Qual é a forma de desenhar currículos no Brasil? Como se constrói sentido em torno dos temas curriculares?

No Fórum de Extensão e de Ação Comunitária das ICES (Forext), o Prof. Paulo Barone (UFRGS) refletiu acerca da construção dos currículos no Brasil. Destacou o caráter quase sempre corporativo desses documentos. Dessa maneira, os currículos se tornam "encaixes" com pouca interconexão e, por vezes, com sobreposição, desperdiçando-se tempo e energia. Tais 
constatações emergem da dicotomização entre conhecer e viver. Quando o conhecimento, enquanto produção, construção e sentido, impossibilita a evidência do sujeito epistêmico e seu reconhecimento no universo cultural, a aprendizagem dá lugar à instrução, impedindo o exercício da cidadania, a corresponsabilidade política e a criação de cultura e seu desdobramento na ciência.

Quando se evidencia a desertificação epistemológica, a aridez cultural e o empobrecimento intelectual e científico, é sinal de que urge repensar as instituições de aprendizagem e de produção do conhecimento. Ao se considerar o currículo como coluna vertebral da educação formal, é ele o grande pivô de todas as transformações pretendidas.

Como é possível notar, para tratar dessa complexidade, é necessário enfrentar e analisar com profundidade o tema do currículo nas IES, bem como os demais documentos que devem sustentar o saber-fazer universitário, debatendo com seus atores e enfrentando cada um dos limites identificados no processo. É nessa direção que trazemos algumas experiências exitosas que buscaram transpor ações pontuais para o conjunto da IES.

Nessa direção, encontramos estudos recentes da Universidade Federal do Paraná - UFPR (KELLER-FRANCO, 2014; FAGUNDES, 2009; PEREIRA, 2012; COUTO, 2013), que descrevem e avaliam novas referências sobre universidade, currículo e formação nesta instituição. O pressuposto geral da proposta da universidade foi enfrentar o paradigma técnico-linear disciplinar que, em suas avaliações, era absolutamente insuficiente. A partir dessa identificação, houve um intenso trabalho de toda a comunidade acadêmica, buscando sustentar o trabalho fundamentado em princípios emancipatórios de desenvolvimento e aprendizagem. Apostou-se na construção do conhecimento a partir de problematizações sociais concretas, construindo os currículos por meio de projetos. Os estudos analisaram documentos e a dinâmica vivida pelos diferentes atores, além de terem sinalizado para abordagens integradas do conhecimento, para relações dialógicas e formativas no processo ensino-aprendizagem-avaliação, entre outras. 
Couto (2013, p. 98-99), utilizando duas experiências (USP e UFPR), as quais afirmaram construir propostas inovadoras em seu PPI e em outros documentos institucionais, definiu que:

[...] um projeto é inovador quando pensa o currículo no eixo da interdisciplinaridade e/ou transdisciplinaridade, com vivências extracurriculares para os estudantes; quando rompe as barreiras entre saber científico/popular, ciência/cultura, teoria/prática; quando busca um questionamento de questões referentes à vida e ao ser humano, levando em consideração ideais democráticos; quando a construção da ciência está pensada dentro de valores éticos e morais; quando há uma produção do conhecimento pautada nas transformações sociais; quando a formação do graduando não é encarada como acabada no período delimitado pela graduação.

A autora constata que ambas as universidades (USP e UFPR) estão inovando e trabalhando a pedagogia universitária. Contudo, em uma delas, o trabalho tem no ensino a sua atividade fundante, sendo a pedagogia universitária e a formação pedagógica muito mais presentes do que na outra, onde o exercício fica submetido à atividade de pesquisador do docente. Sua tese sustenta que a inovação está diretamente relacionada ao modo de organização curricular do conhecimento, ao modo de conceber a relação do graduando com o conhecimento e à metodologia de ensino desenvolvida (COUTO, 2013).

Entendemos que enfrentar comportamentos corporativos e fragmentados do saber; tomar consciência do contexto local e global, com suas redes, pressões e necessidades; e desenvolver uma formação cultural mais ampla, capaz de abarcar problemas típicos de uma sociedade plural e interconectada, assim como envolver os diferentes atores no processo de construir e desenvolver criticamente o currículo, tornam-se elementos mobili- 
zadores, necessários e urgentes para se fazer ante os desafios concretos do nosso tempo. A educação superior, como produto e produtora da sociedade, emerge como meio privilegiado para nuclear as transformações necessárias, considerando-se a força mobilizadora do currículo, a possibilidade de, a partir do tripé ensino-pesquisa-extensão, construir conhecimento com base nos problemas reais que afligem o mundo contemporâneo. Decorre daí a necessidade de se transcender a noção instrucionista do ensino, a visão disciplinar e conteudista do currículo, propondo-se a curricularização de todos os elementos que possibilitem a aprendizagem integral e integradora pela indissociabilidade. Ao se considerar o ponto de partida da gestão em tela, trabalhar-se-á a ideia de curricularização da extensão.

\section{A CURRICULARIZAÇÃO DA EXTENSÃO COMO UMA POTENTE INSTÂNCIA DE SÍNTESE}

A extensão universitária é uma das funções que compõe o tripé acadêmico e, como tal, é parte de um processo formativo de alunos, de professores e de funcionários. Sua inserção já deveria integrar a vida curricular das universidades, envolvendo o coletivo dos estudantes, mas, apesar da legislação vigente, ainda fica circunscrita em torno de um grupo de professores e de alunos que, após selecionados nas vagas disponíveis (em geral poucas), conseguem dispor de tempo para o desenvolvimento dos projetos e das ações dessa natureza.

Conforme já foi mencionado anteriormente, observa-se que a presença da extensão nas universidades sempre foi permeada por relações de poder em torno de que universidade ou de que formação queremos construir. Nessa direção, entendemos que a "curricularização" necessita ser discutida e problematizada, buscando compreendê-la em um contexto mais amplo e mais complexo do que a simples inserção curricular, seja como disciplina, como projeto ou como programa. Ao contrário, sua inclusão 
dentro do formato curricular tradicional poderá ser (mais) um apêndice a satisfazer algumas das nossas ansiedades e/ou exigências legais, correndo o risco de destruir a potência que a extensão pode ter em si, pela sua dialogicidade, porosidade e capacidade de captar distintas realidades.

A curricularização é a compreensão do currículo como um fenômeno que não pode ser distanciado das demandas da realidade, por isso deve transversalizar os currículos, com a singularidade de cada curso e de cada contexto histórico-social, buscando metodologias mais criativas e dinâmicas que resultem, especialmente, em salas de aulas abertas e atrativas para os estudantes.

O Conselho Nacional de Educação/Câmara de Educação Superior (BRASIL, 1997) estabeleceu a orientação geral para as diretrizes curriculares dos cursos de graduação e, dentre outras considerações, destacou o estímulo de práticas de estudo independente, visando a uma progressiva autonomia profissional e intelectual do aluno; o encorajamento do reconhecimento de conhecimentos, habilidades e competências adquiridos fora do ambiente escolar, inclusive os que se referem à experiência profissional julgada relevante para a área de formação considerada; o fortalecimento da articulação da teoria com a prática, valorizando a pesquisa individual e coletiva, assim como os estágios e a participação em atividades de extensão.

No debate realizado no Forext, destacamos a manifestação de Paulo Barone (2014):

"[...] devo dizer que não há nenhuma universidade avançada que atingiu este status sem ter feito da agenda universitária a agenda de um país. Não podemos só nos guiar pelos problemas que interessam às outras sociedades e não à nossa".

Em seu discurso, em palestra proferida e gravada na ocasião do evento, Barone continuou: 
"Eu quero aqui defender que a inserção da extensão no currículo é a aproximação da universidade brasileira com a sociedade. Esse é um movimento absolutamente necessário e difícil de se fazer, no que diz respeito às políticas públicas com as organizações do terceiro setor, com a sociedade [por vezes desorganizada], com a intervenção nos diferentes fóruns (inclusive das universidades), na relação com empresas, na relação com organizações de toda a natureza (sindicais, patronais, etc.). Nessas relações, nós somos capazes de encontrar os elementos da realidade que representam excelentes oportunidades de desenhar currículos com instâncias de síntese. Esta interação também nos permite formar pessoas para a realidade do país, no sentido de elas serem preparadas, primeiro para serem elas mesmas, desenvolverem muito bem os seus potenciais, suas capacidades próprias, sua iniciativa, sua solidariedade, seu sentido ético, mas também sua capacidade de conviver com o diferente, de interagir com o outro, de compreender o outro, de valorizá-lo, de dar voz a ele e de permitir que ele também interfira no seu trabalho. Isso é a mão dupla da extensão". (Acréscimos e grifos nossos).

Destacamos dois aspectos fundamentais para se pensar a inserção da extensão na formação do estudante a partir da contribuição acima: primeiro, um olhar transversalizado (dentro da instituição e com o fora, a sociedade) como formação para a autenticidade. Já o segundo, como formação para a pluralidade e a convivência democrática.

Nessa direção, a concepção ético-política que deveria nortear o esforço para pensar a transversalidade entre extensão, pesquisa e ensino sustentaria uma concepção "avançada" de universidade e, por conseguinte, seria capaz de estabelecer de maneira mais adequada, ou seja, dialógica e conflitiva, a relação entre universidade e sociedade. Dessa forma, pensar de maneira orgânica a relação entre universidade e comunidade passa obrigatoriamente pelo aprofundamento interno da transversalidade entre o tripé 
que constitui a própria universidade. Tarefa irrenunciável da universidade, esta deve ser realizada por ela, em diálogo crítico e construtivo com a sociedade, não podendo ser delegada em hipótese alguma para a sociedade.

Destacamos algumas experiências de curricularização apresentadas na JEM (Jornada de Extensão do Mercosul): o trabalho da Universidad Nacional de Avellaneda (UNDAV), na Argentina, a qual iniciou os seus trabalhos universitários incorporando a extensão aos currículos, por meio de uma ampla discussão entre professores, gestores, alunos e comunidade, o que resultou no Trayecto Curricular Integrador - Trabajo Social Comunitario (TSC), cuja proposta é totalmente integrada às demais funções acadêmicas.

Implica la exploración de estrategias pedagógicas y epistemológicas que contribuyan a dinamizar la construcción de nuevos sentidos y resignificaciones que permitan transgredir, tensionar, transcender el conocimiento instituido, abriendo la posibilidad a laco-producción de conocimiento em relación com los sujetos del territorio al cual pertenece la Universidad. (ÁVILA et al., 2014, p. 9).

A proposta da UNDAV integra pesquisa e extensão ao longo do currículo, com projetos transversais, envolvendo todas as áreas do conhecimento. Em geral, os alunos participam por três ou quatro semestres do TSC, de acordo com o tempo de cada nível de ensino:

Em el primero [...] trabajan aspectos teóricos sobre el sujeto social, procesos histórico [...], la conceptualización de políticas públicas, el problema social, las agendas de intervención, y herramientas metodológicas (con técnicas de la antropología social y otras ciencias, como la entrevista abierta, el registro de campo) para entender y enriquecer cada proyecto. El proyecto de extensión se elabora en el marco de um entendimento com la organi- 
zación que se trate, para ya desde el arranque poner pautas de mutuo interés. No vamos atomarlos como objetos de estudio, ni objeto de capacitación o de práctica profesional. Las organizaciones son partes interesadas y colaborativas em el desarrollo de una actividad que contribuya de algún modo a la transformación o mejora de una situación dada. (ÁVILA et al., 2014, p. 56).

Em el segundo nível del rayecto curricular se trabajan problemáticas em materia de salud, educación, ambiente tomando a una organización concreta como eje ordenador. Luego, em el tercer nivel, mientras continua el proyecto de extensión, avanzamos em la mirada histórica y el proceso de conformación de la organización y em la toma de conciencia sobre los cambios de políticas públicas y sociales em nuestro país. (ÁVILA et al., 2014, p. 59).

Segundo os seus autores, o projeto se encontra em permanente construção e crescimento, além de propor uma aprendizagem em movimento, pois tensiona tanto as práticas docentes quanto a formação profissional dos acadêmicos.

A Universidad de la República do Uruguay (UDR, 2010), em Integralidad: Extension e Perspectivas, Cuaderno de Extension, $n^{\circ} 1$, sintetiza os espaços de formação integral e, neles, principalmente a curricularização da extensão (considerada por eles a segunda Reforma Universitária, sendo a primeira, em 1918, a partir do Manifesto de Córdoba), que oferece diversas modalidades de extensão ao conjunto de atividades educativas da instituição a todos os estudantes de graduação:

De esa manera la formación de nuestros estudiantes tendrá una mayor conexión com la realidad que está más allá de las aulas, vinculando los com situaciones y sectores muy diversos. Ofrecerá oportunidades de afianzar el compromiso ético com la 
mejora de la calidad de vida de la gente, que en particular debemos assumir quiem es hemostenido el privilegio de acceder a la enseñanza superior pública financiada por toda la sociedad. (UDR, 2010, p. 15).

Combinará mejor, de manera moderna, la enseñanza por disciplinas, que es la que predomina em las aulas, com la enseñanza por problemas, que surge cuando distintos actores combinan sus saberes específicos em um processo interactivo orientado a la expansión de la cultura y a la utilización socialmente valiosa del conocimiento. Mostrará a la sociedade con más claridade lo que pueden hacer para el progresso colectivo las personas altamente calificadas y el conocimiento avanzado. $\mathrm{Y}$, por último pero no por ello menos importante, hará una mayor contribución para resolver efectivamente problemas de la comunidade com prioridad a los sectores más postergados. (UDR, 2010, p. 15).

No Brasil, o trabalho desenvolvido pela Universidade Federal do Paraná nos chamou a atenção pela amplitude da proposta, estendendo-se a todas as funções da universidade. Naquela instituição, houve um esforço para que os espaços curriculares de aprendizagem superassem a tradicional organização disciplinar.

São constituídos de três eixos: os Projetos de Aprendizagem, os Fundamentos Teórico-Práticos e as Interações Culturais e Humanísticas. Os projetos ocupam um a dois dias da semana. Nesse espaço, os alunos desenvolvem projetos que ampliam a aprendizagem, aliando os interesses pessoais com as necessidades da comunidade, orientados por professores que os estimulam e desafiam a construir processos autônomos na busca do conhecimento. Os professores também desenvolvem, na região, projetos denominados de Projetos de Ação Docente. A institui- 
ção estimula e promove ações integradas com as políticas públicas, os Projetos Institucionais. (KELLER-FRANCO, 2014, p. 80).

A concretização da curricularização, assim como da indissociabilidade entre ensino, pesquisa e extensão, supõe a realização de projetos coletivos de trabalho, que sejam referenciados na avaliação institucional, no planejamento das ações institucionais e no interesse da maioria da sociedade. Dessa forma, acreditamos que a cada instituição cabe encontrar o seu caminho, correndo riscos e avaliando constantemente o seu processo com o dentro e o fora dela, sem nunca perder de vista a formação para a autenticidade, pluralidade e convivência democrática.

\section{CONSIDERAÇÕES FINAIS}

Por meio da compreensão de que as atividades de extensão contêm um valor intrínseco, com potência para contribuir para a qualidade da formação, bem como de que o currículo pode ser pensado na presença dos atores que o concebem e o usufruem, em ato, propõem-se algumas estratégias de participação da extensão nos processos de construção dos currículos, levando em consideração a integralidade com as funções de ensino e pesquisa como forma de aprender e ensinar.

Entende-se, por essa via, que a chave da mudança perpassa pela construção de um processo formativo ${ }^{10}$ que transversaliza todas as instâncias e envolve a todos, indistintamente, valorizando os espaços comuns capazes de proporcionar a construção de conhecimento pedagógico compartilhado. Em uma investigação que congrega três grupos de pesquisa do país, Bolzan, Isaia e Maciel (2013, p. 50) sintetizam:

${ }^{10}$ Bolzan, Isaia e Maciel (2013) sintetizam a produção e as referências de três grupos que estudam a formação de professores. 
Isso inclui refletir na e sobre a prática pedagógica; compreender os problemas do ensino; analisar os currículos; reconhecer a influência dos materiais didáticos nas escolhas pedagógicas; socializar as construções e as trocas de experiências, de modo a avançar em direção a novas aprendizagens, em um constante exercício de prática reflexiva, colaborativa e coletiva; mobilizar os sujeitos a continuarem aprendendo nos diferentes contextos de atuação. (Grifos nossos).

Considerando-se os argumentos relacionados e desenvolvidos até aqui, postula-se que a gestão, como lócus da projeção de uma série de desejos, expectativas e sonhos daqueles que a sustentam, em sua energia fundadora, tem como tarefa, antes de qualquer empreendimento burocrático ou formal, a gestão dos processos de formação dos sujeitos que compõem o universo legitimador das demandas gerenciais. Com isso, quer se dizer que, antes de tudo, a gestão é gestão das pessoas, de seus desejos e sonhos. Por isso, a missão de promover meios para que os sujeitos se constituam em autores, protagonistas de seus processos de constituição, comprometidos com a construção de uma sociedade promotora da qualidade de vida, responsáveis pela recriação da cultura capaz de sustentar o sonho de humanização alimentado pela humanidade ao longo de milênios, é tarefa primordial de todo gestor ou de toda gestora. No âmbito da gestão universitária, particularmente indicada no início deste capítulo, na Vice-Reitoria de Extensão e Assuntos Comunitários, entendemos que a mobilização das atitudes relacionadas a seguir pode contribuir para a qualidade da formação no âmbito da Universidade de Passo Fundo:

a. Promoção da qualificação docente, na correlação com todos os atores que a compõem, nos distintos contextos onde o professor atua, desde o cotidiano da sala de aula, registrado e refletido, até os eventos mais tipificados, tais como: palestras, seminários ou cursos próprios para esse fim. 
b. A compreensão de que o trabalho docente também se constitui em gestão dos processos de aprendizagem que transcendem a transmissão informativa, embora a englobe. Para isso, é imprescindível o fomento de meios que focalizem a problematização como ponto de partida da construção do conhecimento, a interdisciplinaridade como recurso integrador das áreas e disciplinas, e a realidade como cenário da concretização da aprendizagem significativa e do comprometimento social.

c. A qualificação desse percurso coletivamente, ${ }^{11}$ em um processo no qual poderão ser identificadas as necessidades formativas de cada grupo (colegiados, conselhos de unidades, grupos específicos por projetos, áreas, conhecimentos específicos e pedagógicos) e pactuadas suas responsabilidades com as diretrizes e os princípios das políticas (ensino, pesquisa e extensão), em consonância com os princípios e as diretrizes de outras políticas públicas com as quais a formação/universidade dialoga.

d. A criação de momentos e espaços específicos para acolher docentes e discentes nas suas dúvidas e inquietações relacionadas à implementação de seus estudos, projetos e demais ações.

e. A garantia de apoio e assessoramento aos professores, no que tange à integralidade (indissociabilidade e visão sistêmica, interconectada), às novas metodologias, ao monitoramento e à avaliação das suas ações e a outros processos pedagógicos necessários.

f. O redimensionamento e o fortalecimento das instâncias articuladoras da gestão, por meio de frentes de trabalho nas vice-reitorias, compostas por colegiados permanentes que integrem as assessorias. Dos colegiados emanam as atribuições específicas de planejamento, acompanhamento de processos, proposições, avaliações, formações específicas

\footnotetext{
11 Embora este texto direcione a proposta à extensão, é importante registrar que é impossível desenvolver um projeto dessa natureza sem envolver o todo da gestão. Por isso, mesmo que as contribuições mais específicas das outras áreas não sejam detalhadas aqui, para que o projeto obtenha êxito, elas deverão integrar-se.
} 
e reflexões que sustentam as decisões da gestão. Dessa forma, constitui-se em uma rede transversal de trabalho, conforme a necessidade de cada situação.

g. O estudo de formatos distintos de transversalização, a partir da compreensão da integração e da indissociabilidade, junto a cada curso na discussão de um projeto, na revisão dos PPCs e na proposição de debates com os estudantes, pautando questões acadêmicas e estimulando o engajamento dos mesmos no processo formativo.

h. A promoção de um amplo debate em torno da missão e da vocação da universidade, na discussão externa (nos fóruns de dirigentes da educação, com os parceiros institucionais e com a sociedade em geral).

Um pressuposto fundamental para a indissociabilidade é de que a gestão esteja integrada e trabalhando junto na efetivação da proposta como modo de aprofundamento e validação da transversalização e da indissociabilidade entre extensão, pesquisa e ensino. Nessa direção, a equipe gestora da UPF (mandato 2014-2018) já assumiu a prioridade dessa agenda, colocando-a como estratégica no seu processo de trabalho, proporcionando discussões entre si e/ou com os assessores e/ou outros convidados, na busca de aprofundar, detalhar e subsidiar o projeto e a tomada de decisões.

É preciso considerar que cada instância da universidade tem diferentes formas de desenvolver o seu trabalho, bem como diferentes perspectivas de compreender a formação e o sistema organizativo. É da aproximação dessas diferenças e dos diálogos sistemáticos e contínuos dos grupos que poderemos ter as sínteses para criar a necessidade do outro, do integral, do indissociável e consolidarmos o papel primordial da universidade, que é um todo que se tece junto. Contudo, é preciso cautela e paciência para compreender que uma mudança dessa natureza exige uma capacidade de mobilização coletiva contundente e de tempo. Tempo para maturar, sensibilizar, romper bloqueios burocráticos e eliminar resistências, angústias e anseios ante o desconhecido, o novo. Desse modo, compreendendo que há "muitas universidades dentro da universidade", propomos uma "linha de 
fuga" no sentido Guattariano (de encontrar espaços dentro dessa estrutura maior, que sejam mais flexíveis, desejosos, inventivos e capazes do novo), ou seja, uma vez alinhada a proposta no âmbito da gestão, os grupos de trabalho identificam quais cursos, quais situações ou quais processos encontram mais potência para implementar a proposta de transversalidade. Acredita-se, com base no que já foi apresentado, que esse formato acelera os processos daqueles que estão mais dispostos a iniciar um percurso de mudança, além de disseminar a possibilidade de fazê-la nos espaços mais resistentes, buscando formas singulares para cada situação.

Entende-se, ainda, que a contribuição da extensão na formação deve ser orientada a partir de pressupostos básicos, dentre os quais se destacam:

a. Enfatizar a leitura da realidade;

b. Construir com todos os envolvidos uma postura participativa;

c. Construir uma postura de compreensão, análise e respeito às diferentes características e condições socioeconômicas, além de considerar aspectos culturais, étnicos, geracionais e de gênero presentes nas realidades;

d. Construir habilidades participativas, com vistas à perspectiva da coletividade;

e. Promover uma visão totalizante;

f. f. Promover a construção de uma prática educativa e reflexiva para e com todos os sujeitos envolvidos, desenvolvendo um posicionamento crítico;

g. Facilitar e disseminar o acesso às informações, promovendo a compreensão e a adesão de processos.

Assumir tais posicionamentos consiste, portanto, no ato de autoconhecimento e autoanálise, com um sentido social e político intrinsicamente relacionado a determinados projetos políticos e pedagógicos que pre- 
cisam ser construídos coletivamente (DALBEN; VIANNA; HENRIQUES, 2008). Dessa forma, ao exercitar a gestão como mobilização de uma rede de ações que catalisam a energia dos sujeitos para um projeto comum, potencializam-se os desejos simbolizados no lugar do gestor, legítimo representante das projeções dos sujeitos que o sustentam, direcionando as forças institucionais à execução dos sonhos compartilhados, alimentados, sustentados e tornados realidade nas práticas cotidianas. Caso contrário, apenas juízos de valor e discursos teóricos marcarão o contexto da proposta universitária, pondo em risco o projeto mais amplo, que evidencia a legítima e real vocação da instituição.

\section{REFERÊNCIAS}

AROCENA, R. Curricularización de la extensión: ¿por qué, cuál, cómo? In: UNIVERSIDAD DE LA REPÚBLICA DO URUGUAY - UDR. Integralidad: Extension e Perspectivas. Cuaderno de Extension, n. 1. Montevidéu: Cuadernos/Extensión Universidad de la República, 2010. 108 p. Disponível em: <http://www.extension.edu.uy/system/files_force/Cuaderno_integralidad.pdf>. Acesso em: 10 abr. 2017.

ÁVILA, R. et al. Universidad, territorio y transformación social: reflexiones en torno a procesos de aprendizaje en movimento. Buenos Aires: UNDAV, 2014.

BARONE, P. Conferência proferida. In: ENCONTRO NACIONAL DE EXTENSÃO E AÇÃO COMUNITÁRIA, 21., Campinas, 2014. Campinas: Universidade Mackenzie, 2014. [Gravação independente].

BERTOLIN, J. C. G. Os quase-mercados na educação superior: dos improváveis mercados perfeitamente competitivos à imprescindível regulação do Estado. Educação e Pesquisa, São Paulo, v. 37, p. 237-248, 2011. 
BOLZAN, D. P. V.; ISAIA, S. M. A.; MACIEL, A. M. R. Formação de professores: a construção da docência e da atividade pedagógica na Educação Superior. Diálogo Educacional, Curitiba, v. 13, n. 38, p. 49-68, jan./abr. 2013. BONDÍA, J. L. Notas sobre a experiência e o saber da experiência. Trad. de Corinta Grisolia Geraldi. Revista Brasileira de Educação, Brasília, n. 19, p. 20-29, 2002.

BRASIL. Constituição da República Federativa do Brasil. Brasília: Senado Federal, 1988.

. Lei no 9.394, de 20 de dezembro de 1996. Lei de Diretrizes e Bases da Educação Nacional. Diário Oficial [da] República Federativa do Brasil. Brasília, DF, 23 de dezembro de 1996. Disponível em: <http://www.planalto. gov.br/ccivil_03/Leis/L9394.htm>. Acesso em: 31 jan. 2015.

- Ministério da Educação e do Desporto. Conselho Nacional de Educação. Parecer do Conselho Nacional de Educação/CES/776/97: Orientação para as diretrizes curriculares dos cursos de graduação. Brasília, DF, 03 de dezembro de 1997. Disponível em: <http://portal.mec.gov.br/cne/ arquivos/pdf/CES0776.pdf>. Acesso em: 31 jan. 2015.

. Lei $\mathrm{n}^{\circ} 12.881$, de 12 de novembro de 2013. Dispõe sobre a definição, qualificação, prerrogativas e finalidades das Instituições Comunitárias de Educação Superior - ICES, disciplina o Termo de Parceria e dá outras providências. Diário Oficial [da] República Federativa do Brasil. Brasília, DF, 13 de novembro de 2013. [Edição extra] Disponível em: <http://www. planalto.gov.br/ccivil_03/_ato2011-2014/2013/lei/l12881.htm>. Acesso em: 10 abr. 2017.

. Lei $\mathrm{n}^{\circ} 13.005$, de 25 de junho de 2014. Aprova o Plano Nacional de Educação - PNE e dá outras providências. Diário Oficial [da] República Federativa do Brasil. Brasília, DF, 26 de junho de 2014. [Edição extra] Disponível em: <http://www.planalto.gov.br/ccivil_03/_ato20112014/2014/lei/l13005.htm>. Acesso em: 10 abr. 2017. 
CHAUÍ, M. Brasil, mito fundador e sociedade autoritária. 4. ed. São Paulo: Perseu Abramo, 2001.

COUTO, L. P. A pedagogia universitária nas propostas inovadoras de universidades brasileiras. 188 f. 2013. Tese (Doutorado em Educação) Universidade de São Paulo, São Paulo, 2013.

DALBEN, A. I. L. F.; VIANNA, P. C. M.; HEHRIQUES, A. O. S. Gestão e avaliação da extensão universitária: a construção de indicadores de qualidade. In: ARAÚJO FILHO, T.; THIOLENT, M. J. Metodologias para projetos de Extensão: apresentação e discussão. São Carlos: Cubo Multimídia, 2008.

DALBOSCO, C. A. C. Educação superior e os desafios da formação para a cidadania democrática. Avaliação, Campinas, v. 0, p. 123-142, 2015 b.

. Educação em sociedades tradicionais e sociedades complexas: 0 problema da crise de autoridade. Passo Fundo: UPF, 2015a.

FAGUNDES, M. C. V. Universidade e Projeto Político-Pedagógico: dialógos possíveis fomentando formações emancipatórias. 2009. $210 \mathrm{f}$. Tese (Doutorado em Educação) - Universidade do Vale do Rio dos Sinos, São Leopoldo, 2009.

GARCIA, B. R. Z. A contribuição da extensão universitária para a formação docente. 2012. 264 f. Tese (Doutorado em Educação) - Pontifícia Universidade Católica de São Paulo, São Paulo, 2012.

GUATTARI, F. Caosmose: um novo paradigma estético. Trad. Ana Lúcia de Oliveira e Lúcia Cláudia Leão. Rio de Janeiro: Ed. 34, 1992.

INSTITUTO NACIONAL DE ESTUDOSE PESQUISAS EDUCACIONAIS ANÍSIO TEIXEIRA - INEP. Resumo técnico: censo da educação superior de 2010. Brasília: INEP, 2012.

KELLER-FRANCO, E. Movimentos de mudança: um estudo de caso sobre inovação curricular em cursos de licenciatura da UFPR Litoral. 2014. 
207 f. Tese (Doutorado em Educação) - Pontifícia Universidade Católica de São Paulo, São Paulo, 2014.

MACEDO, R. S. Currículo, diversidade e equidade: luzes para uma educação intercrítica. Salvador: UFBA, 2007.

. Atos de currículo e autonomia pedagógica. Petrópolis: Vozes, 2013.

- Etnopesquisa implicada, currículo e formação. Espaço do Currículo, v. 5, n. 1, p. 176-183, jun./dez. 2012.

MACIEL, A. S.; MAZZILLI, S. Indissociabilidade entre Ensino, Pesquisa e Extensão: percursos de um princípio constitucional. In: REUNIÃO ANUAL DA ANPED, 33., Caxambú, 2010. Anais... Caxambú: ANPED, 2010. Disponível em: <www.anped11.uerj.br/Indissociabilidade.pd>. Acesso em: 12 dez. 2014.

MORAES, M. C. O paradigma educacional emergente. 16. ed. Campinas: Papirus, 2012.

MORIN, E. Os sete saberes necessários à educação do futuro. São Paulo: Cortez, 2000.

. O método V: a humanidade da humanidade. Porto Alegre: Sulina, 2003.

NICOLESCU, B. Manifesto da transdisciplinaridade. Lisboa: Hugin, 2000.

NUSSBAUM, M. C. Sin fines de lucro: por qué la democracia necesita de las humanidades. Buenos Aires: Katz Editores, 2010.

PEREIRA, C. A. Processo de formação de professores universitários engajados no currículo por projetos da proposta integral de educação emancipatória da UFPR/Litoral. 2012. 289 f. Tese (Doutorado em Educação) - Pontifícia Universidade Católica de São Paulo, São Paulo, 2012. 
SANTOS, B. S. A universidade do Século XXI: para uma reforma democrática e emancipatória da universidade. 3. ed. São Paulo: Cortez, 2011.

SANTOS, L. L. C. P. Entrevista com o Professor Antonio Nóvoa. Educação e Sociedade, Campinas, v. 33, n. 119, p. 633-645, abr./jun. 2012. Disponível em: <http://www.cedes.unicamp.brp.635>. Acesso em: 10 abr. 2017.

SILVA, T. T. da. Documentos de identidade: uma introdução às Teorias do Currículo. Belo Horizonte: Autêntica, 1999.

. Mapeando a [complexa] produção teórica educacional: entrevista com Tomaz Tadeu da Silva concedida a Gandin, Paraskeva e Hypolito. Currículo sem Fronteiras, v. 2, n. 1, p. 5-14, jan./jun. 2002. Disponível em: <www.curriculosemfronteiras.org>. Acesso em: 15 mar. 2015.

UNIVERSIDAD DE LA REPÚBLICA DO URUGUAY - UDR. Integralidad: Extension e Perspectivas. Cuaderno de Extension, n. 1. Montevidéu: Cuadernos/Extensión Universidad de la República, 2010. 108p. Disponível em: <http://beu.extension.unicen.edu.ar/xmlui/bitstream/handle/123456789/168/Cuaderno_integralidad.pdf?sequence=1\&isAllowed=y>. Acesso em: 15 mar. 2015.

UNIVERSIDADE DE PASSO FUNDO - UPF. Plano de Desenvolvimento Institucional 2011-2016. Passo Fundo: UPF, 2011. Disponível em: $<$ https:// secure.upf.br/apps/conteudo/resolucoes>. Acesso em: 15 mar. 2015.

- Projeto Pedagógico Institucional. Passo Fundo: UPF, 2009. Disponível em: <https://secure.upf.br/apps/conteudo/resolucoes $>$. Acesso em: 15 mar. 2015.

. Proposta de Gestão da Reitoria Somos Todos UPF: Gestão 20142018. Passo Fundo: UPF, 2014.

YOUNG, M. F. D. O futuro da educação em uma sociedade do conhecimento: o argumento radical em defesa de um currículo centrado em disciplinas. Revista Brasileira de Educação, v. 16, n. 48, set./dez. 2011. 